\title{
HUBUNGAN STATUS PEKERJAAN IBU DAN DUKUNGAN SUAMI TERHADAP PEMBERIAN ASI EKSKLUSIF
}

\section{(Relationship of mother employment status and husband support on exclusive breastfeeding)}

\author{
Ilham Fahrudin ${ }^{1}$, Devi Usdiana Rosyidah ${ }^{2}$, Burhanuddin Ichsan ${ }^{2}$, Tri Agustina ${ }^{2}$ \\ ${ }^{1}$ Mahasiswa Fakultas Kedokteran Universitas Muhammadiyah Surakarta \\ ${ }^{2}$ Dosen Fakultas Kedokteran Universitas Muhammadiyah Surakarta \\ Email: ilhamfahrud@gmail.com \\ Korespondensi: Tri Agustina. Email: ta190@ums.ac.id
}

\begin{abstract}
Breast milk is the best source of nutrition to be given to newborn babies specifically designed to meet all the nutritional needs of a baby during the first six months of life. Many factors affect exclusive breastfeeding including the mother's employment status and husband's support. This study aims to analyze the relationship between mother's employment status and husband's support with exclusive breastfeeding. This study uses a cross sectional approach. Interviews were conducted with 70 breastfeeding mothers with infants over 6 months of age. The method of sampling uses purposive sampling method. The research location in the District of Gatak, Sukoharjo Regency was conducted in December 2019. Statistical analysis was performed bivariately with the chi square test. In this study, the results of chi square for the mother's employment status $p$ value $=0.037$ and husband support $p$ value $=0.244$. There is a correlation between mother's employment status with exclusive breastfeeding and no correlation between husband's support for exclusive breastfeeding.
\end{abstract}

Keywords: Exclusive Breastfeeding, Mother Employment Status, Husband Support

\begin{abstract}
Abstrak
ASI adalah sumber nutrisi terbaik untuk diberikan kepada bayi baru lahir yang dirancang khusus untuk memenuhi semua kebutuhan gizi bayi selama enam bulan pertama kehidupan. Banyak faktor yang mempengaruhi pemberian ASI eksklusif diantaranya adalah status pekerjaan ibu dan dukungan suami. Penelitian ini bertujuan untuk menganalisis hubungan status pekerjaan ibu dan dukungan suami dengan pemberian ASI eksklusif. Penelitian ini menggunakan pendekatan cross sectional. Wawancara dilakukan pada 70 ibu menyusui dengan bayi umur lebih dari 6 bulan. Cara pengambilan sampel menggunakan metode purposive sampling. Lokasi penelitian di Kecamatan Gatak Kabupaten Sukoharjo dilakukan pada bulan Desember 2019. Analisis statistik dilakukan secara bivariat dengan uji chi square. Pada penelitian ini didapatkan hasil chi square untuk status pekerjaan ibu nilai $\mathrm{p}=0.037$ dan dukungan suami nilai $\mathrm{p}=0.244$. Terdapat hubungan antara status pekerjaan ibu terhadap ASI eksklusif dan tidak ada hubungan antara dukungan suami terhadap pemberian ASI eksklusif.
\end{abstract}

Kata kunci: ASI Eksklusif, Status Pekerjaan Ibu, Dukungan Suami 


\section{Pendahuluan}

Air susu ibu (ASI) merupakan makanan yang ideal untuk bayi baru lahir. Allah menyediakan nutrisi yang paling baik untuk bayi yang berupa ASI. Bukti substansial mendokumentasikan keunggulan ASI untuk ibu dan untuk bayi. Bayi sebaiknya diberi hanya ASI saja sampai usia enam bulan kehidupan pertamanya ${ }^{6}$.

ASI adalah sumber nutrisi terbaik untuk diberikan kepada bayi baru lahir yang dirancang khusus untuk memenuhi semua kebutuhan gizi bayi selama enam bulan pertama kehidupan. Nutrisi ASI hadir dalam keseimbangan yang tepat dan disediakan dalam bentuk bioavailable dan mudah dicerna. ASI juga memiliki sifat imunologis dan anti inflamasi yang dapat melindungi ibu dan anak dari berbagai infeksi dan penyakit. Karena itu, menyusui dianggap sebagai salah satu faktor terpenting untuk pertumbuhan dan perkembangan bayi ${ }^{5}$.

ASI dianggap sebagai sumber nutrisi terbaik bagi bayi baru lahir. ASI dapat memberikan manfaat bagi bayi dan juga bagi ibu. Manfaat yang didapat tidak hanya terbatas pada manfaat yang terkait dengan pertumbuhan, imunologi, dan ekonomi, tetapi juga meluas ke ruang lingkup yang lebih besar dengan asumsi mempengaruhi dinamika genetik juga. Selain itu, menyusui telah dikaitkan dengan hasil yang menguntungkan seperti pencegahan penyakit kronis yang tidak menular yang menjadi epidemi global $^{10}$.
Dalam rangka menurunkan angka kesakitan dan kematian anak World Health Organization (WHO) dan United Nations International Children's Emergency Fund (UNICEF) merekomendasikan ASI eksklusif selama 6 bulan pertama kehidupan dan makanan padat pada 6 bulan bersama dengan terus menyusui sampai 2 tahun atau lebih. Namun, tingkat pemberian ASI jauh lebih rendah daripada yang dibutuhkan, dimana hanya sekitar $41 \%$ bayi yang berusia kurang dari 6 bulan disusui secara eksklusif $^{15}$. Di Indonesia cakupan ASI eksklusif pada tahun 2015 secara nasional sebesar 55,7\% masih jauh dari target capaian ASI eksklusif secara global yaitu 80\%. Pada tahun 2018 cakupan ASI ekslusif baru mencapai 41,9\% ${ }^{8}$ Persentase pemberian ASI eksklusif pada bayi 0-6 bulan di jawa tengah pada tahun 2018 sebesar $65,57 \%^{2}$. Di Kabupaten Sukoharjo persentase pemberian ASI eksklusif pada tahun 2018 sebesar 75,8 \% ${ }^{3}$.

Meskipun menyusui bayi sudah menjadi budaya Indonesia, namun upaya meningkatkan perilaku ibu menyusui ASI eksklusif masih diperlukan karena pada kenyataannya praktek pemberian ASI eksklusif belum dilaksanakan sepenuhnya. Salah satu penyebab belum berhasilnya pelaksanaan ASI eksklusif di Indonesia adalah faktor ibu yang bekerja. Pada ibu yang aktif bekerja, upaya pemberian ASI eksklusif seringkali mengalami hambatan lantaran singkatnya masa cuti hamil dan melahirkan mengakibatkan sebelum masa pemberian ASI 
eksklusif berakhir mereka sudah harus kembali bekerja, inilah yang menjadikan bayi tidak memperoleh ASI secara eksklusif, serta banyak ibu yang bekerja beranggapan bahwa ASI nya tidak mencukupi kebutuhan bayi saat ibu bekerja sehingga ibu-ibu memberikan ASI tambahan berupa susu formula ${ }^{1}$.

Suami/ayah memiliki peran yang sangat penting dalam keberhasilan menyusui adalah yaitu sebagai breastfeeding father. Breastfeeding father adalah peran suami dengan cara memberi dukungan kepada ibu menyusui akan mempengaruhi terhadap pemberian ASI eksklusif. Dukungan penuh seorang suami kepada istrinya dalam proses menyusui bayinya meningkatkan keberhasilan menyusui ASI secara eksklusif. Peran breastfeeding father menjadi hal yang wajib dilakukan oleh ayah agar mendukung pemberian ASI eksklusif, sehingga proses menyusui secara eksklusif oleh ibu dapat berjalan dengan sukses. Dukungan suami sangat diperlukan agar pemberian ASI eksklusif bisa tercapai ${ }^{9}$.

Pada penelitian Sihombing didapatkan hubungan antara pekerjaan ibu dengan pemberian ASI eksklusif diperoleh $p$ value sebesar 0,005 (p < 0,05) yang berarti terdapat hubungan bermakna antara pekerjaan ibu dengan pemberian ASI eksklusif $^{12}$. Pada penelitian simanungkalit diperoleh $p$ value sebesar $0,976(\mathrm{p}>0,05)$. Hal tersebut menunjukkan bahwa tidak ada hubungan yang bermakna antara status pekerjaan ibu dengan pemberian ASI eksklusif ${ }^{13}$.

Pada penelitian Kartini didapatkan hubungan antara dukungan suami dengan pemberian ASI eksklusif diperoleh $p$ value sebesar $0,044(\mathrm{p}<0,05)$ yang berarti terdapat hubungan bermakna antara dukungan suami dengan pemberian ASI eksklusif7. Pada penelitian Oktalina diperoleh $p$ value sebesar 0,09 ( $\mathrm{p}>0,05)$. Hal tersebut menunjukkan bahwa tidak ada hubungan yang bermakna antara dukungan suami dengan pemberian ASI eksklusif ${ }^{11}$.

Oleh karena itu, Penelitian ini bertujuan untuk menganalisis hubungan status pekerjaan ibu dan dukungan suami dengan pemberian ASI eksklusif.

\section{Metode}

Penelitian ini merupakan penilitian observasional analitik dengan menggunakan pendekatan cross sectional untuk mempelajari adanya hubungan atau perbedaan prevalensi antar kelompok yang diobservasi, dalam penelitian ini yaitu hubungan antara status pekerjaan ibu dan dukungan suami terhadap pemberian ASI eksklusif. Penelitian ini menggunakan teknik pengambilan sampel secara purposive sampling tetapi untuk teknik sampling ini memiliki kelemahan yaitu tidak mewakili sampel yang dibutuhkan.

Kriteria inklusi pasien yang bersedia menjadi responden penelitian, Ibu yang memiliki bayi berusia lebih dari 6 bulan, responden berdomisili di wilayah kerja Puskesmas Gatak Sukoharjo. Bersedia menjadi 
responden. Kriteria eksklusinya adalah responden tidak hadir ke posyandu saat pengambilan data dan responden tidak mengisi kuesioner secara lengkap.

Pada variabel status pekerjaan ibu menggunakan alat ukur kuesioner dengan hasil ukur (i) ya dan (ii) tidak. Kemudian pada variabel dukungan suami alat ukur kuesioner dengan hasil ukur tidak mendukung (skor 1-20) dan mendukung (skor 21-40). Lalu untuk variabel ASI eksklusif

\section{Hasil dan Pembahasan}

Hasil pada penelitian yang telah dilaksanakan pada ibu anggota Posyandu di wilayah kerja Puskesmas Gatak Sukoharjo menggunakan alat ukur kuesioner dengan hasil ukur Ya (ASI eksklusif) dan Tidak (tidak ASI eksklusif). Responden terdiri dari 70 responden. Pengambilan data dilakukan dengan cara wawancara dan pengisian kuisioner oleh responden yang dilaksanakan di posyandu-posyandu di wilayah kerja Puskesmas Gatak. Analisis data bivariat menggunakan chi square dan diolah menggunakan program SPSS for Windows.
didapatkan karakteristik status pekerjaan ibu dan dukungan suami sebagaimana yang terdapat pada tabel di bawah:

Tabel 1. Distribusi Karakteristik Ibu

\begin{tabular}{lllr}
\hline Karakteristik & Frekuensi & Persent \\
\hline Umur & & & \\
$20-30$ & 40 & $57,1 \%$ \\
$30-40$ & 28 & $40 \%$ \\
$40-50$ & 2 & $2,9 \%$ \\
Total & 70 & $100 \%$
\end{tabular}

Pendidikan Terakhir

$\begin{array}{lcc}\text { Tinggi } & 48 & 68,6 \% \\ \text { Rendah } & 22 & 31,4 \% \\ \text { Total } & 70 & 100 \%\end{array}$

Status Pekerjaan Ibu

Bekerja 
Tidak bekerja

Total
50

70

70

70

\section{$71,4 \%$}

$100 \%$

Dukungan Suami

Mendukung

Tidak mendukung

Total

ASI Eksklusif

Ya

Tidak

Total
Data di atas menunjukan bahwa berdasarkan umur ibu anggota posyandu mayoritas berusia 20-30 tahun sebanyak 40 responden $(57,1 \%)$. Berdasarkan pendidikan terakhir ibu, mayoritas responden adalah ibu dengan pendidikan tinggi, yaitu sebanyak 48 responden $(68,6 \%)$. Berdasarkan status pekerjaan ibu, mayoritas responden adalah ibu tidak bekerja, yaitu sebanyak 50 responden $(71,4 \%)$. Berdasarkan dukungan suami mayoritas responden mendapatkann dukungan dari suami, yaitu sebanyak 54 responden
$75,7 \%$

$100 \%$
$47,1 \%$

$52,9 \%$

$100 \%$

$(77,1 \%)$. Berdasarkan data di atas didapatkan responden yang memberikan ASI secara eksklusif sebanyak 33 responden $(47,1 \%)$ dan yang tidak memberikan ASI secara eksklusif sebanyak 37 responden $(52,9 \%)$.

Analisis bivariat digunakan untuk mengetahui hubungan antara variabel independen dengan dependen yang dianalisis melalui uji chi square. Analisis bivariat dikatakan bermakna jika nilai $\mathrm{p}$ $<0,05$ dan sebaliknya.

Tabel 2. Hasil Analisis Bivariat

\begin{tabular}{|c|c|c|c|c|}
\hline \multicolumn{5}{|c|}{ Pemberian ASI eksklusif } \\
\hline \multirow[t]{2}{*}{ Variabel } & & & \multirow[t]{2}{*}{ Nilai $p$} & \multirow[t]{2}{*}{ OR } \\
\hline & $\mathrm{Ya}$ & Tidak & & \\
\hline Status Pekerjaan Ibu & & & 0,037 & 0,262 \\
\hline \multirow[t]{2}{*}{ Bekerja } & 5 & 15 & & \\
\hline & $25 \%$ & $75 \%$ & & \\
\hline \multirow[t]{2}{*}{ Tidak bekerja } & 28 & 22 & & \\
\hline & $56 \%$ & $44 \%$ & & \\
\hline \multirow[t]{2}{*}{ Total } & 33 & 37 & & \\
\hline & $47,1 \%$ & $52,9 \%$ & & \\
\hline
\end{tabular}


Dukungan Suami

0,398

1,904

Mendukung

Tidak mendukung

Total
27

$50,9 \%$

6

$35,3 \%$

33

$47,10 \%$
26

$49,1 \%$

11

$64,7 \%$

37

$52,90 \%$
Pada variabel status pekerjaan ibu, hasil uji statistik

chi square diperoleh nilai $\mathrm{P}<0,05(\mathrm{P}=0,037)$, maka dapat disimpulkan bahwa ada hubungan yang bermakna antara pekerjaan ibu terhadap pemberian ASI eksklusif. Dari hasil juga didapatkan odds ratio 0,262 yang berarti ibu bekerja memiliki risiko 0,262 kali untuk memberikan ASI daripada ibu yang tidak bekerja. Penelitian ini sejalan dengan penelitian Sihombing, menyatakan bahwa ada hubungan bermakna antara status pekerjaan ibu dengan pemberian ASI eksklusif, dengan nilai $\mathrm{P}=0,005$ dimana dari 37 responden yang tidak bekerja, ada 21 responden yang memberikan ASI eksklusif pada bayinya dan dari 17 responden yang bekerja, ada 15 responden yang tidak memberikan ASI eksklusif pada bayinya $^{12}$.

Selain itu pada penelitian Waluyo, disebutkan bahwa semakin tinggi beban kerja mental yang dialami oleh tenaga kerja dapat menyebabkan kelelahan kerja (job burnout). Kelelahan kerja sendiri merupakan salah satu indikator terhadap stres kerja. Stress yang terjadi pada ibu yang sedang menyusui dapat memperlambat pelepasan hormon oksitosin ke aliran darah sehingga dapat mengganggu produksi ASI. Akibatnya ASI yang keluar menjadi lebih sedikit yang menimbulkan persepsi ketidakcukupan ASI pada ibu menyusui. Hal inilah yang menyebabkan ibu menyusui memilih untuk menambahkan susu formula kepada anaknya dan menjadi jarang memberikan ASI yang akhirnya membuat produksi ASI terhenti karena produksi ASI mengikuti hukum supply meets demand (suplai tergantung permintaan $)^{14}$.

Hasil uji statistik chi square variabel dukungan suami diperoleh nilai $\mathrm{P}>0,05(\mathrm{P}=0,398)$, maka dapat disimpulkan bahwa tidak ada hubungan yang bermakna antara dukungan suami terhadap pemberian ASI eksklusif. Penelitian ini sejalan dengan penelitian Fakhidah \& Rosita, dimana tidak terdapat hubungan yang signifikan antara dukungan suami terhadap pemberian ASI eksklusif ${ }^{4}$.

Dukungan suami adalah salah satu bentuk interaksi yang didalamnya terdapat hubungan yang saling memberi dan menerima bantuan yang bersifat nyata yang dilakukan oleh suami terhadap istrinya. Dukungan yang suami berikan secara terus menerus 
dapat mempengaruhi keberhasilan ibu dalam menyusui. Faktor internal yang mempengaruhi dukungan suami adalah faktor emosi dan pendidikan serta tingkat pengetahuan. Faktor eksternal yang mempengaruhi dukungan suami adalah latar belakang budaya, status pekerjaan dan struktur keluarga ${ }^{4}$.

Banyak faktor yang dapat mempengaruhi pemberian ASI eksklusif antara lain umur, pendidikan, dan status pekerjaan. Termasuk didalamnya adalah dukungan sosial terutama dari keluarga terdekat yaitu suami. Keberhasilan menyusui sangat ditentukan oleh peran ayah karena ayah akan turut menentukan kelancaran refleks pengeluaran ASI yang sangat dipengaruhi oleh keadaan emosi atau perasaan ibu. Faktor lain yang memungkinkan tidak ada hubungan antara dukungan suami dalam pemberian ASI eksklusif yaitu masih banyak suami yang berpendapat bahwa menyusui adalah urusan ibu dan bayinya. Selain itu faktor pekerjaan dan kelelahan bekerja juga sangat mempengaruhi dukungan suami yang diberikan ${ }^{16}$.

Penelitian ini tidak mengadopsi faktor-faktor lain yang berhubungan pemberian ASI eksklusif, misalnya faktor pendidikan ibu, pendapatan keluarga, usia ibu, status gizi ibu dan lain sebagainya. Pengambilan sample pada penelitian menggunakan purposive sampling yang merupakan kekurangan penelitian kuantitatif.

\section{Simpulan}

Status pekerjaan ibu memiliki hubungan yang bermakna terhadap pemberian ASI eksklusif dan dukungan suami tidak memiliki hubungan yang bermakna terhadap pemberian ASI eksklusif. Bagi peneliti selanjutnya diharapkan dapat melakukan penelitian lebih lanjut dengan metode penelitian yang lebih baik untuk mengetahui hubungan antara status pekerjaan ibu dan dukungan suami terhadap pemberian ASI eksklusif.

\section{Daftar Pustaka}

1. Bahriyah, F., Putri, M. \& Jaelani, A. K., 2017. Hubungan Pekerjaan Ibu terhadap Pemberian ASI Eksklusif pada Bayi. Journal Endurance, 2(2), pp. 113-118.

2. Dinas Kesehatan Jawa Tengah, 2019. Profil Kesehatan Provinsi Jawa Tengah Tahun 2018. Available from: http://dinkesjatengprov.go.id/v2018/dokumen/pr ofil_2018/mobile/index.html\#p=80

3. Dinas Kesehatan Kabupaten Sukoharjo, 2018. Profil Kesehatan Kabupaten Sukoharjo Tahun 2018. Available from: https://dkk.sukoharjokab.go.id/download/profil/ Tabel\%20Profil\%20Kab.\%20Sukoharjo\%20201 8.pdf

4. Fakhidah, L. N. \& Rosita, S. D., 2019. Dukungan Suami dengan Kesiapan Ibu dalam Pemberian ASI pada Bayi di Puskesmas Bulu Kabupaten Sukoharjo. Jurnal Publikasi 
Kebidanan, 10(1), pp. 70-79.

5. Hossain, M., Islam, A., Kamarul, T. \& Hossain, G., 2018. Exclusive Breastfeeding Practice During First Six Months of an Infant's Life in Bangladesh: A Country Based Cross-Sectional Study. BMC Pediatrics, 18(93), pp. 1-9.

6. Ichsan, B., Wibowo, B. H. \& Sidiq, M. N., 2015. Hubungan Lama Pemberian Air Susu Ibu dengan Prestasi Akademik Siswa Kelas 1 Sekolah Dasar Ar Risalah Kartasura Sukoharjo. Biomedika, 7(2), pp. 8-12.

7. Kartini, N. K. A., Martini, N. K. \& Suwitra, I. M., 2018. Hubungan Pengetahuan Ayah dan Breastfeeding Father terhadap Pemberian ASI Eksklusif di Wilayah Kerja Puskesmas Mengwi III. Jurnal Kesehatan Terpadu, 2(2), pp. 91-96.

8. Kemenkes, 2018. Rahasia Anak Berkembang Optimal dan Tidak Mudah Sakit Beri ASI Eksklusif dan Pola Asuh Tepat. Available from: https://www.depkes.go.id/article/view/1808210 0002/rahasia-anak-berkembang-optimal-dantidak-mudah-sakit-beri-asi-eksklusif-dan-polaasuh-tepat.html

9. Kusumayanti, N. \& Nindya, T. S., 2017. Hubungan Dukungan Suami dengan Pemberian ASI Eksklusif di Daerah Perdesaan. Media Gizi Indonesia, 12(2), pp. 98-106.

10. Mahesh, P. K. B. et al., 2018. Effectiveness of Targeting Fathers for Breastfeeding Promotion: Systematic Review and Meta-Analysis. BMC
Public Health, 18(1140), pp. 1-14.

11. Oktalina, O., Muniroh, L. \& Adiningsih, S., 2015. Hubungan Dukungan Suami dan Dukungan Keluarga dengan Pemberian ASI Eksklusif pada Ibu Anggota Kelompok Pendukung ASI (KP-ASI). Media Gizi Indonesia, 10(1), pp. 64-70.

12. Sihombing, S., 2018. Hubungan Pekerjaan dan Pendidikan Ibu dengan Pemberian ASI Eksklusif di Wilayah Kerja Puskesmas Hinai Kiri tahun 2017. Jurnal Bidan "Midwife Jurnal", 5(1), pp. 40-45.

13. Simanungkalit, H. M., 2018. Status Pekerjaan Dan Pengetahuan Ibu Menyusui Terhadap Pemberian ASI Eksklusif. Jurnal Info Kesehatan, 16(2), pp. 236-244.

14. Waluyo, H. W. P., E., Widjasena, B. \& Denny, H. M., 2019. Hubungan Beban Kerja Mental terhadap Pemberian ASI Eksklusif pada Ibu Bekerja di Wilayah Kerja Puskesmas Karangjati. Jurnal Kesehatan Masyarakat, 7(4), pp. 226-231.

15. WHO, 2018. GLOBAL BREASTFEEDING SCORECARD, 2018 - Enabling Women to Breastfeed Through Better Policies and Programmes. Available from: https://www.who.int/nutrition/publications/infan tfeeding/global-bf-scorecard-2018.pdf?ua=1

16. Yuliana, S. A., Ernawati, Y. \& Febriani, H., 2019. Hubungan Dukungan Sosial Suami 
dengan Keberhasilan Pemberian ASI Eksklusif

di Desa Madurejo Prambanan. MIKKI, 8(2), pp.

61-68. 